\title{
Metal Nanoparticles and Carbon-Based Nanostructures as Advanced Materials for Cathode Application in Dye-Sensitized Solar Cells
}

\author{
Pietro Calandra, Giuseppe Calogero, Alessandro Sinopoli, and Pietro Giuseppe Gucciardi
}

CNR, Istituto per i Processi Chimico-Fisici, Sede di Messina, Salita Sperone, C.da Papardo, 98158 Faro Superiore Messina, Italy

Correspondence should be addressed to Giuseppe Calogero, calogero@me.cnr.it

Received 31 December 2009; Revised 12 February 2010; Accepted 25 February 2010

Academic Editor: Gaetano Di Marco

Copyright ( $) 2010$ Pietro Calandra et al. This is an open access article distributed under the Creative Commons Attribution License, which permits unrestricted use, distribution, and reproduction in any medium, provided the original work is properly cited.

We review the most advanced methods for the fabrication of cathodes for dye-sensitized solar cells employing nanostructured materials. The attention is focused on metal nanoparticles and nanostructured carbon, among which nanotubes and graphene, whose good catalytic properties make them ideal for the development of counter electrode substrates, transparent conducting oxide, and advanced catalyst materials.

\section{Introduction}

A photovoltaic cell (PC) is a device converting incident light to electrical energy. Dyes-sensitized solar cells (DSSCs) are devices devoted to the conversion of solar energy into electricity based on a large band gap nanocrystalline semiconductor sensitized by a dye which is chemically linked to the semiconductor surface and has substantial absorption in the visible range. The nanocrystalline DSSC technology was pioneered by Gräetzel in the early nineties and its best conversion efficiency reported is more than $10 \%$ [1]. DSSCs have emerged as an important low in cost photovoltaic technology. A DSSC, as shown in Figure 1, consists of a transparent photoanode, an electrolyte solution containing a redox couple $\left(\mathrm{I}^{-} / \mathrm{I}_{3}{ }^{-}\right)$and a counter electrode (CE) sandwich type assembled.

The photoanode consists of a film of titanium oxide nanoparticles deposited onto a conductive glass coated with a thin layer of doped Fluorine Tin oxide (FTO-Glass). The sensitizer is usually a ruthenium polypiridine complex. The principal photophysical and redox processes for a DSSC are listed below:

$$
\mathrm{D}+\mathrm{h} v \longrightarrow \mathrm{D}^{*}
$$

$$
\begin{gathered}
\mathrm{D}^{*}+\mathrm{TiO}_{2} \longrightarrow \mathrm{D}^{+}+\mathrm{e}_{\mathrm{cb}}{ }^{-}\left(\mathrm{TiO}_{2}\right) \\
\mathrm{D}^{*} \longrightarrow \mathrm{D} \\
2 \mathrm{D}^{+}+3 \mathrm{I}^{-} \longrightarrow 2 \mathrm{D}+\mathrm{I}_{3}{ }^{-}, \\
\mathrm{D}^{+}+\mathrm{e}_{\mathrm{cb}}{ }^{-}\left(\mathrm{TiO}_{2}\right) \longrightarrow \mathrm{D}+\mathrm{TiO}_{2}, \\
\mathrm{I}_{3}^{-}+2 \mathrm{e}^{-}(\text {catalyst }) \longrightarrow 3 \mathrm{I}^{-}, \\
\mathrm{I}_{3}{ }^{-}+2 \mathrm{e}_{\mathrm{cb}}\left(\mathrm{TiO}_{2}\right) \longrightarrow 3 \mathrm{I}^{-}+\mathrm{TiO}_{2} .
\end{gathered}
$$

Under irradiation of light at frequency $v$, the dye is excited to state $\mathrm{D}^{*}(1)$. The dye is chosen in such a way that its electronic excited state lies energetically above the conduction band $(\mathrm{cb})$ edge of the semiconductor nanoparticles. In these conditions, the electron injection to the semiconductor (2a) can occur successfully, competing with the deactivation reaction (2b). In order to achieve a high current generation the oxidation of iodide (3a) and reduction of iodine (4a) must effectively compete with the charge-separated 


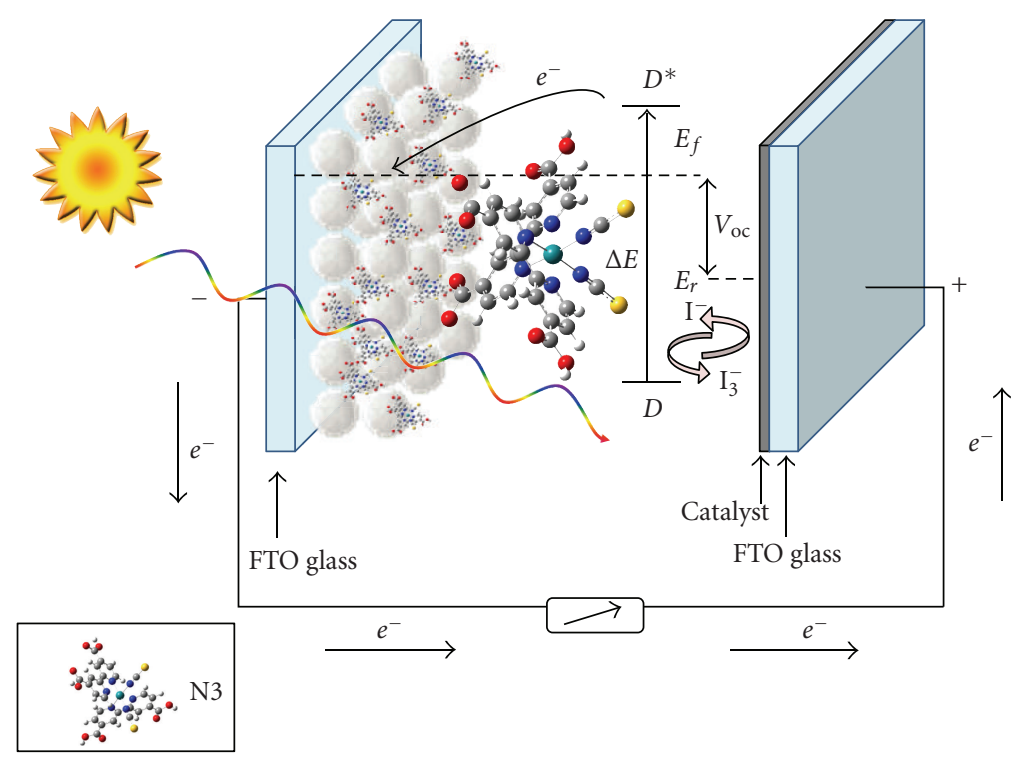

FIGURE 1: Schematic representation of the DSSC, based on a dye ruthenium-based (N3), to indicate the electron energy level and electron flux in different processes. The cell voltage $\left(\mathrm{V}_{\text {oc }}\right)$ observed under illumination corresponds to the difference $\Delta \mathrm{V}$ between the quasi-Fermi level of titanium and the electrochemical potential of the electrolyte.

states recombination reactions $(3 \mathrm{~b})$, (4b) which decrease the current production. Usually synthetic inorganic compounds such as Ruthenium (II) complexes with carboxylated polypyridyl ligands, especially $\left[\mathrm{Ru}(\mathrm{II})\left(2,2^{\prime}\right.\right.$-bipyridyl-4, $4^{\prime}$ dicarboxylic-acid) ${ }_{2}(\mathrm{NCS})_{2}$ ] (called $\mathrm{N} 3$ ), are employed as molecular sensitizers (D) in DSSCs [2]. A mixture of $\mathrm{I}_{3}{ }^{-} / \mathrm{I}^{-}$ ions in organic solvents commonly serves as charge carriers; Sapp et al. [3] have recently developed a new redox couple based on Cobalt organometallic complexes. The sealing procedures in assembling a DSSC are of key importance. An optimal sealing is necessary to prevent the electrolyte loss by leakage and/or the solvent evaporation, requiring the use of sealing materials resistant to the electrolyte corrosion.

Finally, another essential component for a long-time operation of the DSSC is the counter electrode, the place where the regeneration of the charge mediator (4a) takes place. The role of the counter electrode is twofold: first, it transfers electrons arriving from the external circuit back to the redox system, and second, it catalyzes the reduction of the oxidized charge mediator. Main requirements for a material to be used as counter electrode in a DSSC are a low chargetransfer resistance and high exchange current densities for the reduction of the oxidized form of the charge mediator [4]. Furthermore, such materials must possess chemical and electrochemical stability in the electrolyte system used in the cell. One of the best catalyst materials providing high exchange current for this reduction is platinum. But even graphite-based materials could be used as low cost cathode materials [5].

In a PC generation of electrical power under illumination is achieved by the photovoltaic device capability to produce a voltage over an external load and a current through the load at the same time. Several physical parameters are used to assess the PC performances. When the cell is short circuited under illumination, the current (called short circuit current, $\mathrm{I}_{\mathrm{sc}}$ ) is at its maximum but the voltage is zero; on the other hand, under open circuit conditions, the voltage reaches its maximum value (called the open circuit voltage, $\mathrm{V}_{\mathrm{oc}}$ ) and the current is zero. So in a typical current versus voltage curve, the point maximising the current*voltage product defines the cell maximum power ( $P \max )$. Another important parameter to assess the solar cell performance is the fill factor (FF), namely, the ratio of the cell maximum power (Pmax) over the product $\mathrm{V}_{\mathrm{OC}}{ }^{*} \mathrm{I}_{\mathrm{sc}}$.

In this minireview we report the state of the art of the two main catalyst materials type used in DSSC such as metal and carbon-based nanostructures (Figure 2) for cathodes preparation. One of the characteristics of the cathodes, also named counter electrodes (CEs), is the ability to keep the overvoltage low at photocurrent densities up to $20 \mathrm{~mA} / \mathrm{cm}^{2}$. So far, platinum has been the preferred material for the CE since it is a good catalyst for the triiodide reduction. A light reflecting $\mathrm{CE}$ is usually employed, consisting of a conducting TCO glass onto which a $2 \mu \mathrm{m}$ thick Pt mirror is deposited by sputtering, as shown in Figure 3. Our sputtering system consists of an RF-magnetron of 150 watts of power which generally works at low pressure $\left(10^{-5}-10^{-3}\right.$ torr $)$ under an $\mathrm{N}_{2}$ gas flow. This kind of preparation is, however, too expensive for large-scale production. For such applications, and in order to obtain transparent devices, the procedure to prepare the CE consists (see Figure 4) in (1) spreading a small quantity of a hexachloroplatinic acid solution $(5 \mathrm{mmol}$ $\mathrm{L}^{-1}$ ) in isopropanol on the conductive surface of a glassFTO electrode and (2-4) heating the coated electrode at $500^{\circ} \mathrm{C}$ for 15 minutes (as shown in Figure 4). Otherwise, it is possible to use electrodeposition methods, were a platinum plate and a FTO-glass where used as anode and cathode, respectively. The electrodeposition is usually performed at 


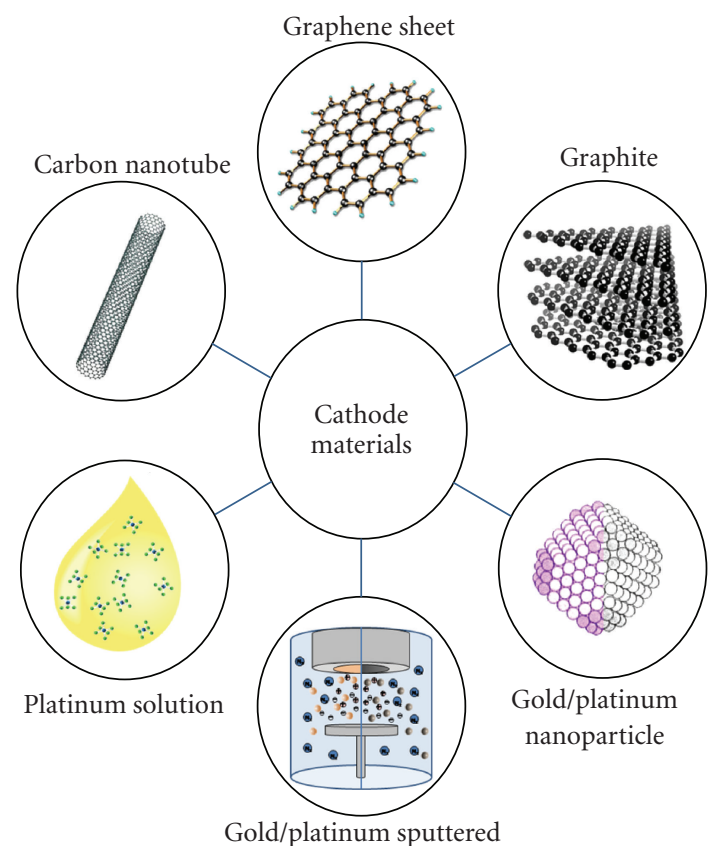

FIGURE 2: Schematic representation of the materials which can be used in DSSC as catalyst.

constant current ( $10 \mathrm{~mA}$ for 3 seconds in a $0.002 \mathrm{M} \mathrm{H}_{2} \mathrm{PtCl}_{6}$ aqueous solution).

In principle, even a fine Pt powder could be used, but for a thin platinum layer of $50 \mathrm{~nm}$, is a large amount of metal $\left(1 \mathrm{~g} / \mathrm{m}^{2}\right)$ necessary. This amount could be reduced using a porous substrate of conducting material. However, the platinum might dissolve in the electrolyte solution by slow oxidation and complex formation as $\mathrm{PtI}_{4}$ or $\mathrm{H}_{2} \mathrm{PtI}_{6}$ [6]; this could redeposit on the $\mathrm{TiO}_{2}$ surface and shortcircuit the cell by catalyzing the recombination process (4b). In metal nanoparticles, the porosity of the powder and the stability of the metal crystals could be combined. Another interesting material alternative to platinum in DSSC is carbon; it combines low cost, corrosion resistance, sufficient conductivity, catalytic activity, heat stability, and easy manipulation.

Porous carbon cathode is easily prepared from graphite powder dispersed in liquid solvent deposited on a conductive substrate and dried. To increase the catalytic activity and for a good adherence avoiding scratch of the carbon layer a binder $\left(\mathrm{TiO}_{2}\right.$ paste) is required. The resulting composite is fired at $450^{\circ} \mathrm{C}$ and a layer of $50 \mu \mathrm{m}$ is necessary for an optimal conductivity [5].

For educational purposes a CE can be made by simply blackening a FTO glass with a pencil.

\section{Advanced Counter Electrodes}

2.1. Metal Nanoparticles. As mentioned above, in the optics of ever improving DSSC performance it turns out that the cathode material is required to provide high exchange current. This means that the available catalytic surface in the electrode plays a crucial role in determining the overall device current. So we recently focused attention on the preparation of rough/porous electrodes which, being characterised by a higher surface, are expected to assure a higher number density of catalytic sites. The metal film preparation and its deposition onto the cathode will influence the final film structure/properties and ultimately the final device performance. In this framework, it is obvious that the use of nanoparticles, that is, particles whose size is in the nanometer range, results to be the answer to the need of advanced, highsurface materials.

Generally the strategies inspiring any synthetic method are roughly divided into two categories: the bottom-up and the top-down approaches. The distinction arises from the starting point in the synthetic route to prepare nanoparticles: being nanoparticles in between molecular species and macroscopic samples, their synthesis can be achieved:

(i) from macroscopic precursors through subsequent subdivision in ever smaller particles by strong milling of solids or through lithographic processes, and this is the philosophy of the top-down approach (sputtering, laser ablation, vapour phase deposition, lithography, etc.)

(ii) starting from their atomic and molecular precursors, through chemical reactions and modulating their self-assembling in order for nanoparticles to have desired structural and/or morphological characteristic, which is the philosophy of the bottom-up approach.

It is important to point out that, whatever the approach used, there is not any best synthetic method for all materials, but each one has its advantages and disadvantages and can reveal efficient for some classes of materials but not 


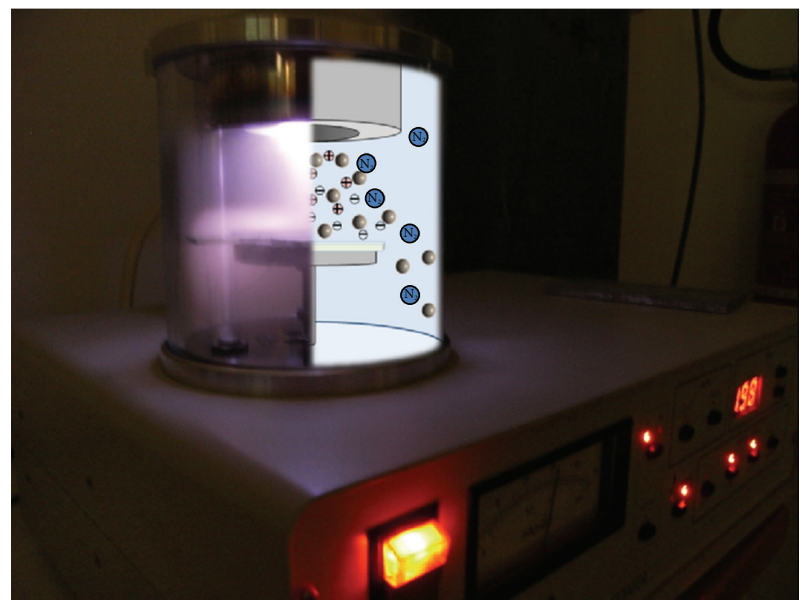

Figure 3: Sputtering system for metal deposition.

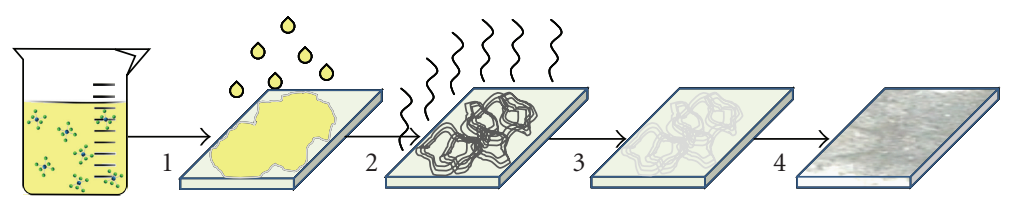

FIGURE 4: Schematic representation of the steps involved in preparation of $\mathrm{Pt}$ thin film in DSSC counter electrodes by means of hexachloroplatinic acid solution.

suitable for others. So, in the last few decades a wide range of protocols have been set up and now it is possible to synthesise nanoparticles of every kind of size and shape and of almost any kind of materials. However, the choice of the synthetic method must therefore take into account for it and be finalised to the subsequent use of the nanoparticles.

In this framework, top-down approaches (sputtering itself has been used to prepare also nanoparticles) [7-9] are generally quite expensive and resource-consuming; on the other hand chemical methods, which are typical bottomup techniques, are generally cheaper and better fit for large scale applications. Moreover, since chemical methods allow in principle the control at a molecular level, we believe that they are to be preferred in view of advanced applications.

Other advantages of chemical methods are as follows:

(i) they all are rapid;

(ii) the synthesis can be carried out at room temperature;

(iii) they allow a fine size and polydispersity control;

(iv) in principle, they can be implemented to prepare 2D and/or 3D nanoparticle arrays.

Going deeper into details, the leading philosophy is to exploit the natural tendency toward specific self-aggregation exhibited by certain complex systems so chemical methods are generally based on the use of microheterogeneous systems (colloids, liquid crystals, gels, and micellar solutions). Moreover particles are suspended like colloids and, being the particle size usually less then $100 \mathrm{~nm}$, these systems are optically clear and suitable for optical absorption investigations and this constitutes another specific advantage.
Incidentally, since this approach works at the atomic level, it is easy to prepare interesting nanocomposites by coating or doping, for example, nanoparticles with other materials in desired amount at mild conditions. Analogous procedures by top-down approaches involving bulk materials as starting materials would be more difficult: they would require extreme conditions as high temperatures to enhance thermal diffusion $[10,11]$.

The presence of the solvent or other molecules can represent a drawback since they can be actually regarded as "contaminants" that need to be removed making the synthesis "dirty".

Generally, metal nanoparticles are produced in a liquid ("liquid chemical methods") by reduction of chloroauric acid or hexachloroplatinate $\left(\mathrm{HAuCl}_{4}\right.$ or $\left.\mathrm{H}_{2} \mathrm{PtCl}_{6}\right)$. After dissolving the desired precursor, a reducing agent is added. This causes metal ions to be reduced to neutral metal atoms. As more and more of these atoms form, the solution becomes supersaturated, and the metal gradually starts to precipitate in the form of sub-nanometer particles. The rest of already formed metal atoms/clusters tend to stick to the existing particles, and so do the successively formed atoms/clusters.

This is the reason why, especially for the chemical synthesis of nanoparticles in liquid media, the achievement of stable nanoparticles is of crucial importance. This is not a trivial point since nanoparticles tend spontaneously to grow with no limits. The thermodynamic reason is obvious, that is, the trend to minimize the surface contribution to the total free energy.

In fact the free energy $(G)$ of a phase depends, at constant pressure and temperature, on the surface $A$ through the 
surface tension $\gamma$ :

$$
d G_{\text {surface }}=\gamma d A \text {. }
$$

Now, $\gamma$ is usually positive, reflecting the fact that the surface atoms are in a high-energy state; so nanoparticles have the natural tendency to reduce this contribution by minimizing the surface-to-volume ratio. This results in a natural nanoparticle tendency to growth, which can take place through a wide number of mechanisms: agglomeration, coalescence, ripening, and so forth.

Detailed discussions on the possible mechanisms of nanoparticle growth can be found in the literature $[12,13]$.

From another point of view, the driving force of any growth process is the surface atoms attempt to form bonds in order to complete their coordination structure. Incidentally, it can be expected that and the more efficient is the saturation of surface dangling bonds by growing, the more powerful is the driving force to grow. Hence, an efficient synthetic protocol should inhibit nanoparticle growth allowing the size control in the nanosize regime.

This can be achieved basically by the following:

(1) adsorption of suitable molecules at the nanoparticle surface, the role of such molecules is twofold: first, they act as surface-active molecules reducing the nanoparticle interfacial energy, and, secondly, they coat the nanoparticle with a protective shell preventing them from ripening/coalescence;

(2) charging of particles; so charged nanoparticles cannot aggregate owing to the repulsive interparticle forces;

(3) compartmentalization in distinct domains; so nanoparticles cannot come into contact to aggregate.

Of course the microscopic processes enabling growth inhibition are of utmost importance in determining the microscopic structure of the nanoparticles and, consequently, their properties.

Effective stability against the thermodynamically spontaneous unlimited growth can be conferred to nanoparticles by the use of a particular molecules which are able to bind nanoparticle surface.

In this case, nanoparticle stabilization can be obtained through the aid of the so-called "steric" stabilizer, generally constituted by polymers that are able to form complex with the metal precursor. After metal reduction with the formation of nanoparticles, further nanoparticles growth is inhibited by steric effects due to the presence of the polymer. The production of (catalitically active) metal sols by aqueous methanol reduction of metal salts in the presence of a steric stabilizer was first reported by Hirai and coworkers [14-16].

They studied the mechanism of particle formation in the Rh-poly(vinyl alcohol)-methanol-water systems but they also demonstrated similar syntheses of platinum sols, including the reduction of $\mathrm{H}_{2} \mathrm{PtCl}_{6}$ by aqueous methanol solution in presence of poly (vinyl pyrrolidone).

Another method for nanoparticle stabilization, based on the same approach, relies on the use of "chemical" stabilizer exploiting the capability exhibited by some chemical species (as thiols, thioethers, sulphides, phosphines, amines, etc.) to form stable bonds with metal surface. The moleculemetal link allows nanoparticle coating and formation of a monolayer of opportunely oriented molecules. It is worth noting that if on the one hand this inhibits all the aforementioned mechanism of agglomeration/coalescence preserving nanoparticles from their growth, on the other hand this opens new directories in the controlled synthesis of macrostructures combining nanoparticles characteristics and molecular properties which can be exploited in sensors design, in the controlled drug delivery, and so forth.

Obviously different molecules possess different affinity towards metal surface so different degrees of stabilisation can be obtained. It is worth to highlight here that the strongest nanoparticle stabilisation can be obtained by the use of alkylic thiols and in particular those with alkylic chains with a number of $\mathrm{C}$ atom between 6 and $18\left(\mathrm{C}_{6}-\mathrm{C}_{18}\right)$.

However, when such nanoparticles are exploited as enhanced catalysts as in DSSC, an easy accessibility of their surface to reacting species is needed. This requirement can be fulfilled by choosing easily displaceable coating agents, that is loosely adsorbed on the nanoparticle surface or by a stabilisation mechanism based on the surface charge adsorption.

Following this strategy, an important method was proposed by Turkevich in 1951 and refined by Frens in 1970s, which allows the synthesis of $20 \mathrm{~nm}$ golden, water-soluble, nanoparticles stabilised by citrate [17-19].

In this method, the sodium citrate first acts as a reducing agent. At the first step an extensive networks of gold nanowires is formed as a transient intermediate [20], after which gold nanoparticle formation takes place. The negatively-charged citrate ions are adsorbed onto the gold nanoparticles, introducing the surface charge that repels the particles and prevents them from aggregating. The reduction in the amount of sodium citrate as a consequence of the redox reaction will reduce the amount of the citrate ions available for stabilizing the particles, and this will cause the small particles to aggregate into bigger ones until the total surface area of all particles becomes small enough to be covered by the existing citrate ions.

Generally, this method is used to produce modestly monodisperse spherical gold nanoparticles suspended in water of about $10-20 \mathrm{~nm}$ in diameter. Larger particles can be produced by reducing the amount of sodium citrate but this comes at the cost of monodispersity and shape.

The most popular procedure to prepare Platinum nanoparticles by citrate reduction of $\mathrm{PtCl}_{6}{ }^{2-}$ is described by Aika et al. (1976) [21]. Since citrate does not have a strong capability of linking gold nanoparticles, the stability is quite poor and an aggregation/coalescence usually occurs in short time.

Facing this problem Devi and rao [22] set up a method for the preparation of platinum nanoparticles from platinous chloride $\left(\mathrm{K}_{2} \mathrm{PtCl}_{4}\right)$ by reduction with $\mathrm{H}_{2}$ and simultaneous addition of capping polymer material (sodium polyacrylic acid). The size of platinum nanoparticles was controlled by changing the ratio of concentration of a capping polymer 
material, but, as it can be seen, the problem of an easily displaceable capping agent to prepare a surface-accessible nanosized catalyst again emerges. Better results can be obtained by a method based on the reaction path proposed by Brust et al. in 1994 for golden nanoparticle synthesis through chemical reduction of an $\mathrm{Au}$ (III) complex [23] with the only difference that the capping agent is not used.

The method is schematically depicted in scheme 1: briefly a $\mathrm{Au}$ (III) complex, usually $\mathrm{HAuCl}_{4}$, is transferred to an organic phase (usually toluene) through tetraoctyl ammonium bromide (TOAB). The $\mathrm{Au}(\mathrm{III})$ to $\mathrm{Au}(0)$ reduction is performed by adding an aqueous solution of $\mathrm{NaBH}_{4}$ to the same reaction mixture. This simple procedure allows the preparation of 5-6 $\mathrm{nm}$ golden nanoparticles [24] although the size can be tuned by changing the experimental conditions; moreover the method has been used by us also for the synthesis of platinum nanoparticles simply by replacing the $\mathrm{HauCl}_{4}$ precursor salt with $\mathrm{H}_{2} \mathrm{PtCl}_{6}$. In this reaction, TOAB is both the phase transfer catalyst and the stabilizing agent. Nanoparticle stabilisation occurs via the charge adsorption at the nanoparticle surface (the surfactant is responsible for this) without the use of any capping agent, so that the system is stable for a significant time. We would like to point out here an aspect that could be of utmost importance: a nanoparticle stabilisation without surface functionalisation with organic molecules implies a "nude" nanoparticle surface. This means that such nanoparticles can be chemically adsorbed onto a desired substrate establishing with it electrical junction, which is of utmost importance in the fabrication of photoelectrochemical devices.

The need for nanoparticle surface accessibility, the need of stabilising the particles in the nanometer regime, as well as the need to fulfil specific application specimens have inspired a wide variety of synthetic strategies have been exploited for this purpose such as photochemical [25] or controlled chemical reductions [26, 27], combined action of deposition/precipitation processes [28], ultrasound-induced reduction [29], and chemical reduction in microheterogeneous systems [30].

In this ambit, in the optics of avoiding the use of capping agents, which are chemically bonded to the metal nanoparticle surface, of particularly interest are surfactants because they are generally physically and reversibly adsorbed. A particularly successful method exploits solutions of watercontaining reversed micelles as reaction and stabilizing media leading to quite monodisperse gold nanoparticles and allowing to control their size and shape simply by changing surfactant nature and/or system composition [31]. Using these systems, Chiang considered the possibility to obtain gold nanoparticles simply by chemical reduction of $\mathrm{Au}$ (III) salt with hydrazine, both dissolved in the aqueous core of reversed micelles according to the reaction

$$
4 \mathrm{HAuCl}_{4}+3 \mathrm{~N}_{2} \mathrm{H}_{4} \longrightarrow 4 \mathrm{Au}+16 \mathrm{HCl}+3 \mathrm{~N}_{2}
$$

showing that nanoparticle size control can be achieved by changing the $\mathrm{HAuCl}_{4}$ to hydrazine molar ratio. However, the resulting nanoparticle radius was never less than $50 \AA$. This is a considerable drawback because enhanced catalytic activity is expected for smaller nanoparticles.
In order to reach this goal, the confinement in dry reversed micelles using a simple and successful method [32] has been set up in the last few years. The proposed method scheme is depicted in Scheme 2.

The overall procedure consists in the following steps (i) entrapment of appropriate amount of the $\mathrm{HauCl}_{4}$ in the hydrophilic core of water-containing reversed micelles dispersed in apolar solvent, (ii) complete evaporation of volatile components (water and apolar solvent) of the saltcontaining micellar solution, and (iii) resuspension of the salt/surfactant composite in apolar solvent leading to the formation of dry dispersions of salt nanoparticles coated by opportunely oriented surfactant molecules. The successive addition of a reductant solution $\left(\mathrm{N}_{2} \mathrm{H}_{4}\right.$ /tetrahydrofuran $)$ leads to the formation of $\sim 14 \AA$ gold nanoparticles [33].

The advantages of this method are

(i) the presence of very small nanoparticles,

(ii) water absence, which reduces drawbacks such as inherent instability and secondary reactions.

However, the most recent trend is directed towards the setting up of protocols avoiding the side products coming from chemical reduction leading to the metal nanoparticle formation. As already said, in fact, the chemical synthesis major drawback is the presence of side-products that could negatively affect not only nanoparticle physicochemical properties but also their catalytic activity, since they can most probably cause catalyst poisoning. So, the use of low-cost physical methods to produce high-purity metal nanoparticles, followed by their entrapment in surfactant solutions, could be an effective solution of the aforementioned problem.

An interesting example is given by the method we proposed in 2006, based on the combined action of the Solvated Metal Atom Dispersion (SMAD) technique and the confinement in anhydrous reversed micellar solution. In that work, we have exploited the SMAD technique to produce solvated gold atoms which were entrapped in n-heptane solutions of dry sodium bis(2-ethylhexyl)sulfosuccinate reversed micelles.

Scheme 3 shows schematically the procedure. Briefly, a metal filament was heated by Joule effect through a tuneable current: under certain conditions the heating causes the evaporation of metal atoms which are then collected by a controlled flow of cooled sodium bis(2ethylhexyl)sulfosuccinate (AOT) micellar solution. In such conditions, competition between gold nanoparticle growth within the micellar core and surfactant adsorption on the nanoparticle surface leads to fast and complete inhibition of gold nanoparticle growth. By the combined action of SMAD technique and surfactant adsorption, two populations of gold nanoparticles confined in AOT liquid crystals were obtained. Owing to the soft coating of bigger Au nanoparticle by AOT molecules, these populations can be easily separated by resuspension of the solid nanocomposite in n-heptane. This leads to the formation of a precipitate of big (20$50 \AA$ ) Au nanoparticles, and a surnatant retaining the smaller size ones stabilising those with an optimal size. The high 


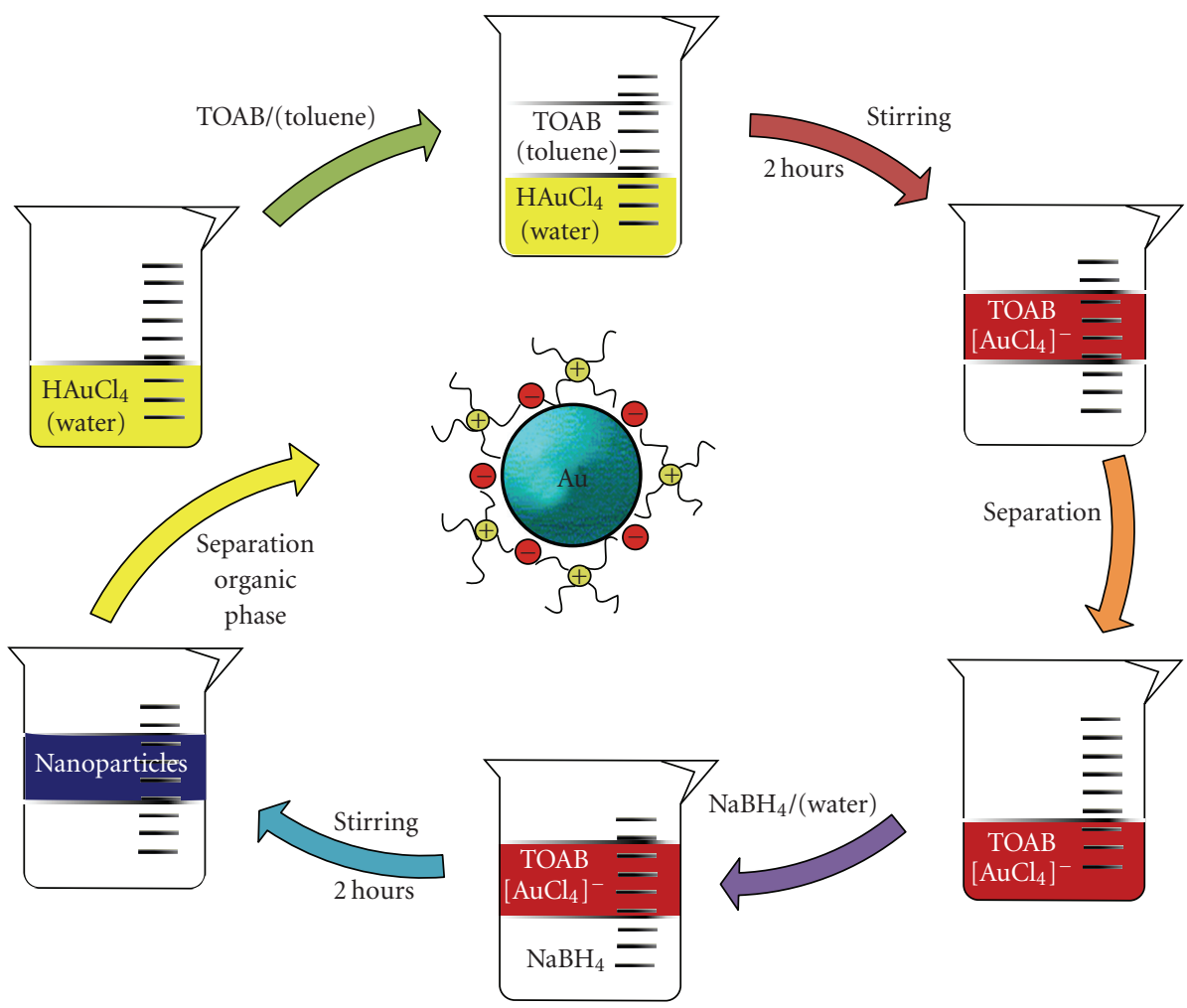

Scheme 1: Scheme showing the synthetic steps involved in the Brust synthesis of gold nanoparticles. The method can be used to synthesize platinum nanoparticles by replacing the precursor salt to $\mathrm{H}_{2} \mathrm{PtCl}_{6}$.

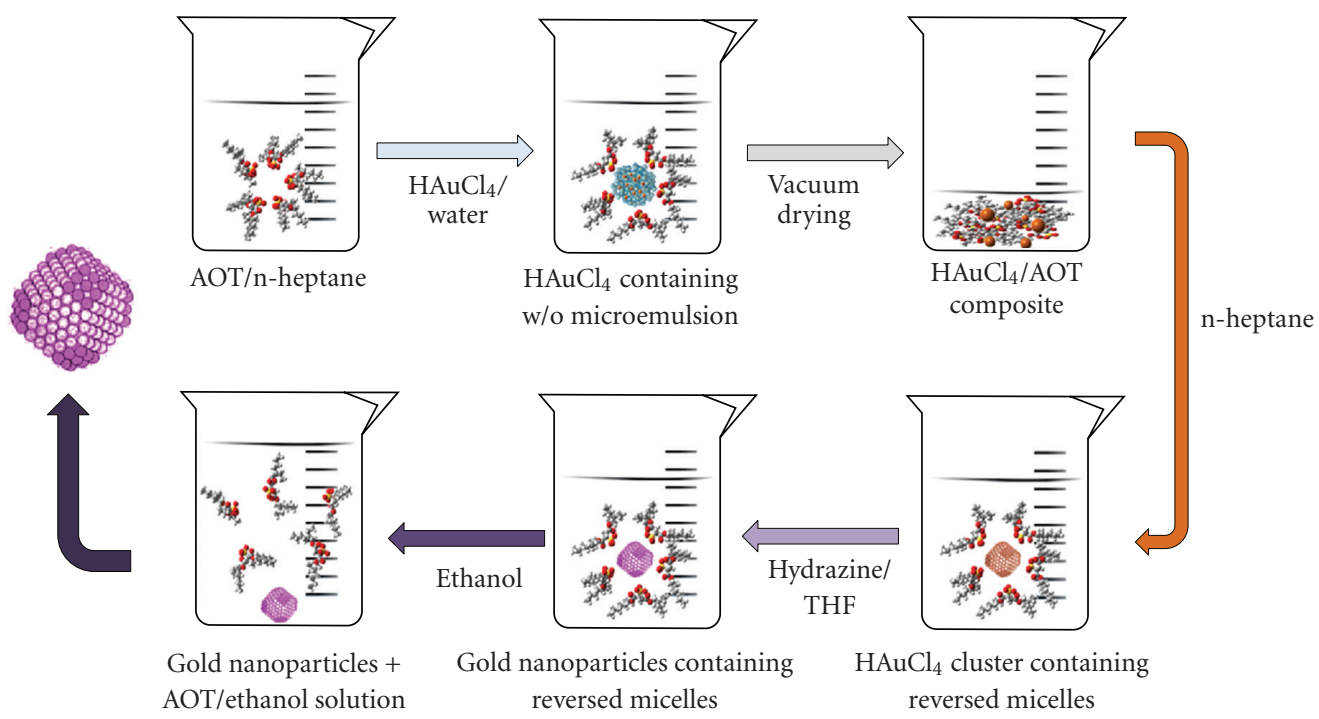

Scheme 2: The protocol for gold nanoparticle synthesis based on the confinement of $\mathrm{HAuCl}_{4}$ salt precursor in dry reversed micelles and its subsequent reduction to form $\sim 14 \AA$ gold nanoparticles proposed by Calandra et al. [33].

AOT affinity for n-heptane, AOT polar headgroup specific interactions with gold nanoparticles and the presence of dispersion interactions were individuated to be the microscopic factors responsible for the observed behaviour. The relative proportions of these two populations should be varied by appropriate selection of the experimental procedure.
To conclude this brief survey on advanced techniques for metal nanoparticle preparation, it is worth to mention the recent experimental generation of gold particles by sonolysis, because of their low environmental impact. In such process, an aqueous solution of $\mathrm{HAuCl}_{4}$ with glucose is used [34] and the reducing agents are hydroxyl and sugar pyrolysis radicals 


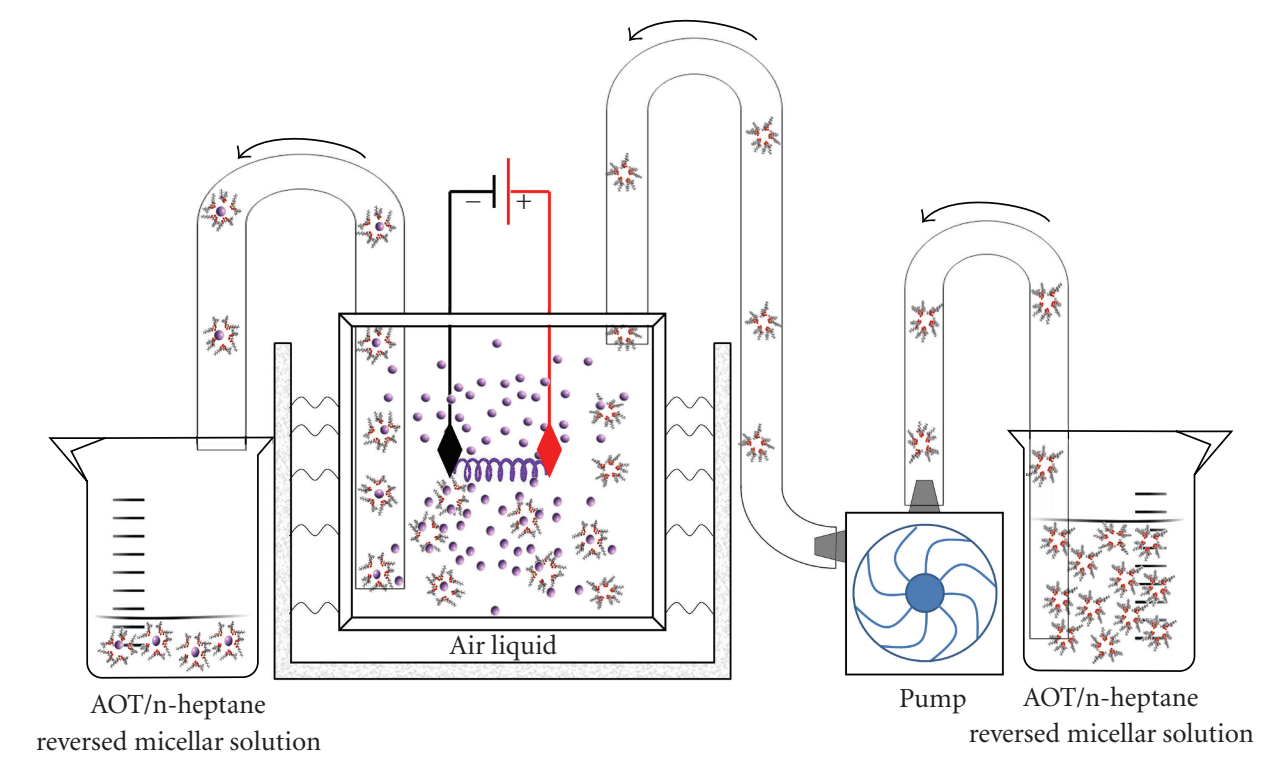

containing gold nanoparticles

mrmm Heated gold filament

Scheme 3: Schematic mechanism of the method proposed by Calandra et al. [33], based on the combined action of the Solvated Metal Atom Dispersion (SMAD) technique and the confinement in anhydrous reversed micellar solution.

(formed at the interfacial region between the collapsing cavities and the bulk water). The obtained morphology is that of nanoribbons with width $30-50 \mathrm{~nm}$ and length of several micrometers. These ribbons are very flexible and can bend with angles larger than $90^{\circ}$ so that they can form high interfacial surface skeins. Spherical particles can also be obtained by replacing glucose with cyclodextrin.

2.2. Carbon Nanostructured Materials. Nanotechnology seems to help a lot in solar cells improvement. During the last decade, nanomaterials have emerged as new building blocks for constructing light-energy-harvesting assemblies, for the improvement of the cell efficiency and temporal stability [35]. Recent research in solar cell technology shows that a film of carbon nanotubes could replace two of the layers normally used in a solar cell, with improved performance and reduced costs. Carbonaceous materials feature good catalytic properties, electronic conductivity, corrosion resistance towards iodine, high reactivity, abundance, and low cost [36, 37]. In 1996 Kay and Gräetzel. demonstrated the importance of the high surface area introducing carbon black powder in graphite counter electrodes to enhance its catalytic activity [5]. Since then, other research groups have employed Different carbon-based nanostructures such as graphite, carbon black, activated carbon, fullerene, hard carbon sphere, carbon nanotubes (CNTs) and graphene [38-47].

Single Wall Carbon Nanotubes (SWNTs) are made by rolling up a single graphene sheet $[48,49]$ with fullerene like end-cap [50] (see Figure 5). Because the structure of carbon nanotubes is closely related to that of graphene, nanotubes are generally labelled in terms of the graphene lattice unit vectors $\mathbf{a}_{1}$ and $\mathbf{a}_{2}$. The structure can be specified or indexed by its circumferential vector $\left(\mathbf{C}_{h}\right)$, defined as the chiral vector which connects two crystallographically equivalent sites on a graphene sheet. In this way, the geometry of an SWNT is completely specified by the chiral vector, defined as

$$
\mathbf{C}_{h}=n \mathbf{a}_{1}+m \mathbf{a}_{2}
$$

where the pair of integers $(n, m)$ are the so-called chiral indexes. The diameter $d$ of the nanotube can be estimated from the following equation:

$$
d=\left|\frac{\mathbf{C}_{h}}{\pi}\right|=\frac{\sqrt{3} a_{C-C}}{\pi} \sqrt{n^{2}+n \cdot m+m^{2}}
$$

where $a_{c-c}$ is the length of the $\mathrm{C}-\mathrm{C}$ bond. The chiral vector $\mathbf{C}_{h}$ uniquely defines a particular $(n, m)$ tube, as well as its chiral angle $\theta$, being the angle between $C_{h}$ and $a_{1}$. The chiral angle $\theta$ is given by

$$
\theta=\tan ^{-1}\left[\frac{\sqrt{3} m}{m+2 n}\right] .
$$

The value of $\theta$ is in the $0^{\circ} \leq \theta \leq 30^{\circ}$ range, due to the hexagonal symmetry of the graphene lattice. The chiral angle also determines the tilt angle of the hexagon with respect to the nanotubes axis direction. This diameter and chirality dependence generates an interesting structural aspect, that is, the importance of structurally defined categories and families of nanotubes of different physical properties. For instance, nanotubes with $\bmod [(2 n+m), 3]=1$ or 2 are of 


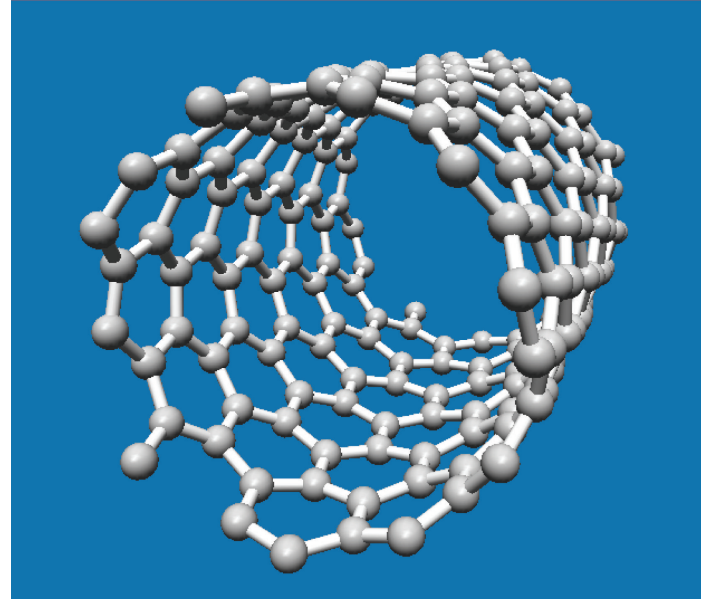

Figure 5: Schematic representation of a Single wall carbon nanotube (SWNT).

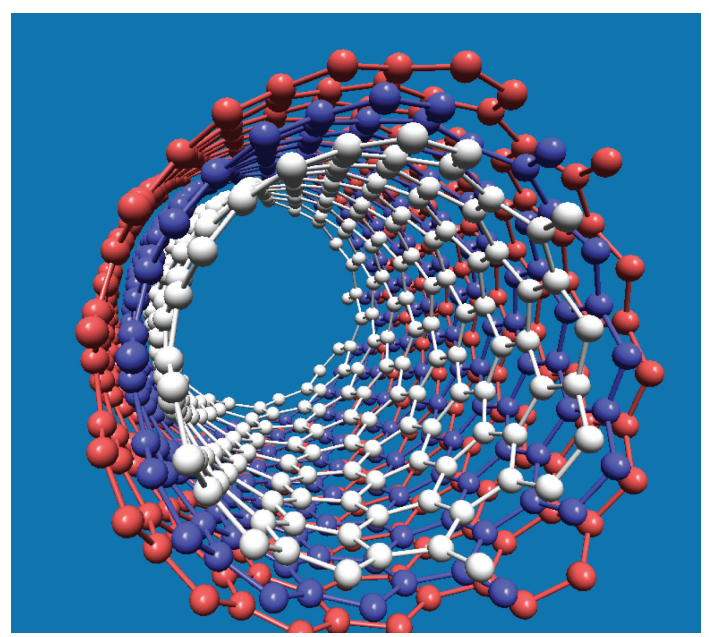

FIGURE 6: Schematic representation of a Multi wall carbon nanotube (MWNT).

semiconducting nature (type 1 or type 2 ), while tubes having $\bmod [(2 n+m), 3]=0$ are metallic [51].

Multiwall nanotubes (MWNTs) consist of multiple concentric SWNTs with random chirality making them metallic on average (see Figure 6) [52].

The unique electrical and electronic properties, wide electrochemical stability window, and high surface area have prompted many researchers to employ SWNTs assemblies for energy conversion and storage devices [53-60]. Fullerenes, for example (see Figure 7), exhibit rich photochemistry and act as an electron shuttle in photochemical solar cells [61, 62]. They also play an important role in improving the performance of organic photovoltaic cells [63].

In a typical photochemical solar cell, a semiconducting film serves as a photoactive electrode that upon excitation with visible light generates electron-hole pairs. As one of the charge carriers (e.g., the electron) is driven to the counter electrode, the other charge carrier (e.g., the hole) is scavenged by a redox couple present in the electrolyte, thus

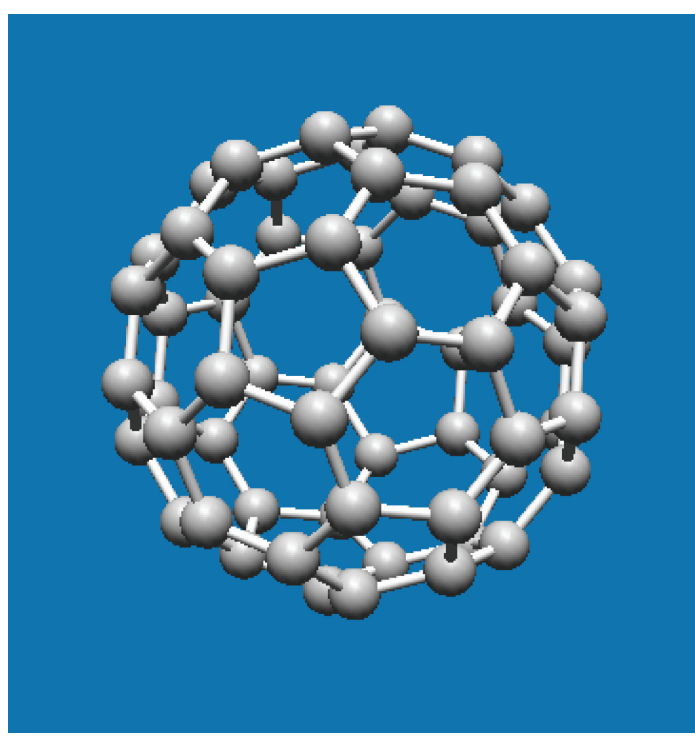

FIGURE 7: Schematic representation of a fullerene.

generating a photocurrent. Commercially available SWNTs contain both metallic and semiconducting nanotubes with different chirality. The work function of SWNT bundles is known to be about $-4.8 \mathrm{eV}$ versus absolute vacuum scale (AVS). Carbon nanotubes are characterized by a bandgap usually occurring in the $0-1.1 \mathrm{eV}$ range, depending upon their chirality and diameter $[53,63]$. As-purchased SWNTs powders consist of bundles and ropes of nanotubes with random chiralities [64-66], losing their specific mechanical, thermal, and optical properties [67-70]. For optical characterization (determination of transition energies, chiralities, diameter distribution, etc.) of the SWNTs samples, a procedure for debundling and individualization is needed [71-74]. Ultrasonication in water-surfactant solutions is used to disaggregate the nanotubes bundles. The presence of the surfactant molecules guarantees the encapsulation of individual tubes, preventing reaggregation phenomena due to the strong surface forces [65]. Large impurities can be removed by filtration. A final ultracentrifugation step allows for separating the supernatant, rich of individual and small nanotubes bundles, from large residual bundles and insoluble materials [75-77]. In Figure 8 some samples prepared at IPCF-CNR (Istituto per i Processi ChimicoFisici-Consiglio Nazionale delle Ricerche) in Messina are shown. SWNT films also show a high electrochemical activity in the iodide/tri-iodide redox reaction because of the onedimensional nanofeature of SWNTs which can provide better electron transport. In detail, the redox reaction involved in a DSSC is catalyzed by the counter electrode.

In DSSCs with a liquid electrolyte, the conversion efficiency becomes higher by using nanocarbon electrodes because of their high surface areas, which enhances the electrochemical activity of the electrode. The recent development of depositing ultra-thin and homogeneous CNT films on transparent glass electrodes can be conveniently realized with the benefit of lowering the process cost and improving 


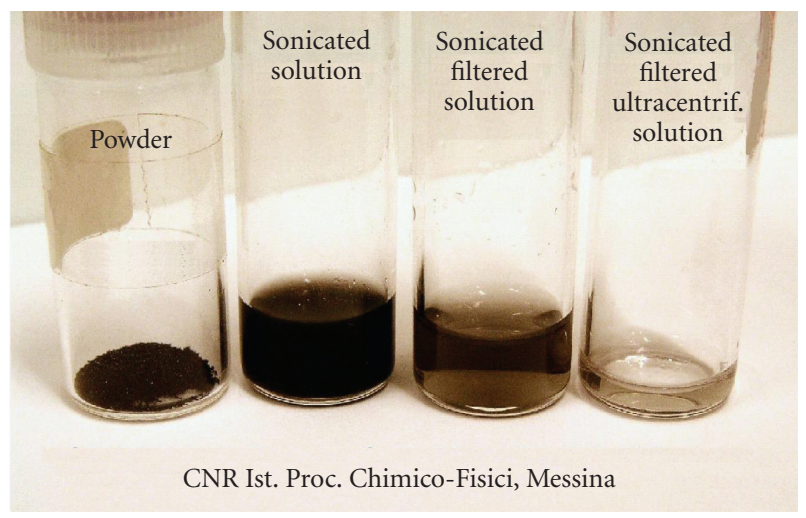

FIGURE 8: Pictures of the result of the debundling and dispersion process: from powders (left) to solutions of individual SWNT after ultracentrifugation (right).

the mechanical flexibility. Carbon nanotubes, in particular, combine advantages such as high electrical conductivity, chemical stability, and high surface area with good electrochemistry and catalytic properties making them suitable for applications in many energy conversion technologies such as catalytic counter electrode materials in DSSCs [78]. In particular, CNTs are efficient to catalyze the tri-iodide reduction and, thus, are good candidates to replace Platinum in DSSCs. The diameters of MWNTs are in the order of 3-10 nm, while SWNTs have the smallest diameters $(<2 \mathrm{~nm})$. These materials exhibit very large aspect ratios $\left(>10^{3}\right)$ and establish percolation pathways that can provide the means for high carrier mobility and an efficient charge transfer. Despite high catalytic activity towards $\mathrm{I}_{3}{ }^{-}$reduction, nanocarbon counter electrodes pose additional risks to the stability of DSSC, since the electrolyte made upon nanocarbon powders prolong exposure in corrosive iodine/iodide redox electrolyte may lead to the detachment of loosely bound particles from the rest of the electrode promoting dark current and degrade the device performance. Lee et al. [78]. investigate the effect of dark and room temperature aging on the performance of carbon powder counter electrode based DSSC. The cathode was prepared by mixing Carbon powders $(20 \mathrm{~nm})$ with an organic binder dissolved in aqueous solutions. The resulting homogenous paste was coated on FTO by doctor blading and sintered at $250^{\circ} \mathrm{C}$ for 1 hour; after DSSC $\mathrm{TiO}_{2}$ electrode and carbon counter electrode were sandwiched with 80 micron thick polymer foil as a spacer, sealing was done by keeping the structure in a hot-press at $100^{\circ} \mathrm{C}$ for few seconds. The liquid electrolyte consisting of $0.5 \mathrm{M} \mathrm{LiI}, 0.05 \mathrm{M} \mathrm{I}$, and $0.5 \mathrm{M}$ TBP in acetonitrile was introduced into the cell gap through predrilled hole on the counter electrode. Finally, the electrolyte injection hole was firmly sealed with surlyn and microscope cover glass. Under these conditions the carbon counter electrode shows a mesoporous structure facilitating the diffusion of the $\mathrm{I}_{3}{ }^{-}$ions, making the entire carbon film accessible to iodide ions. This yields DSSC performances similar to those employing Pt-counter electrodes, with $\mathrm{Voc}=0.79 \mathrm{~V}$,
$\mathrm{Jsc}=16 \mathrm{~mA} / \mathrm{cm}^{2}, \mathrm{FF}=0.645$, and efficiency $=7.56 \%$. Studies carried out on the aging of this devices showed a decrease of only $16 \%$ of the performances over 60 days. Huang et al. [79] reported on the use of hard carbon spherules (HCS), a disordered carbon material, as counter electrode for DSSCs. HCS was prepared following the method reported in the literature [80]. Carbon counter electrode was prepared by screen-printing a slurry of carbon powder, conductive carbon black (30 nm average size) and polyvinylidene fluoride (PVDF) in N-methyl-2-pyrrolidone (NMP) onto the FTO glass substrate. Then the counter electrode was dried in vacuum oven at $100^{\circ} \mathrm{C}$ overnight. The cathode was integrated in a standard DSSC using a $\mathrm{TiO}_{2}$ (average particle size $21 \mathrm{~nm}$ ) film deposited on FTO, immersed in the dye (N3) and organic solvent-based liquid electrolyte $(0.6 \mathrm{M}$ dimethylpropylimidazolium iodide, $0.1 \mathrm{M}$ of iodine, $0.5 \mathrm{M}$ tert-butylpyridine, and $0.12 \mathrm{M}$ of lithium iodide in 3-methoxyacetonitrile). When comparing the photocurrent-voltage characteristics of DSSCs using the HCS and sputtered $\mathrm{Pt}$ as the counter electrode it is found that the efficiency of HCS is slightly lower than Pt $(5.7 \%$ against $6.5 \%$ ), but notably higher than graphite $(3.8 \%)$, indicating that the electrochemical activity of HCS is higher than graphite (containing $20 \%$ of carbon black). Koo et al. [81] investigated the possibility of using multi wall CNTs (MWCNT) as a new long stability counter electrode materials. DSSCs were made according to standard procedures, employing nanoporous $\mathrm{TiO}_{2}$ films on FTO glass, N3 dyes $\left[\mathrm{Ru}(\mathrm{II})\left(2,2^{\prime} \text {-bipyridyl-4, } 4^{\prime} \text {-dicarboxylic-acid }\right)_{2}(\mathrm{NCS})_{2}\right]$ and the $\mathrm{I}^{-} / \mathrm{I}_{3}{ }^{-}$couple as redox electrolyte. Sealing was accomplished with Amosil 4 (Solaronix, SA). Counter electrodes were prepared by mixing multi wall carbon nanotubes powders (10-20 $\mathrm{nm}$ average diameter, $5 \mu \mathrm{m}$ in length) with deionized water and Carboxyl Methyl Cellulose, mechanically ball-milled for 24 hours. The obtained paste was deposited on FTO glass using doctor blade method and then dried at $70^{\circ} \mathrm{C}$ for 10 hours in air, thus obtaining a CNT film $\sim 20-25 \mu \mathrm{m}$ thick. The authors reported a higher efficiency (8\%) with respect to Pt-sputtered and electrodeposited 
electrodes (5-6\%), as well as a longer stability ( $>5$ days compared with 3 days of Pt-electrodes). The better efficiency was attributed to a larger active area and good conductsivity of the counter electrode. On the other hand, a higher stability against the electrolyte was found with respect to sputtered Pt counter electrodes and no detachment of CNT from the FTO glass was observed through electrochemical impedance spectroscopy measurements. Carbon nanotubes, thanks to their electrochemical activity, are efficient in catalyzing the reduction of triiodide so they are able to replace platinum in the DSSC [82]. Platinum was found to degrade over time while in contact with an iodide/triiodide liquid electrolyte, reducing the efficiency of a DSSC, whereas carbon nanotubes did not. The combination of high conductivity and transparency of carbon nanotubes films means that carbon nanotubes may be able to replace the TCO layer used in the DSSC as well as the platinum catalyst. (The transparency and conductivity also gives carbon nanotube films an advantage over other alternative catalysts, such as carbon black films, which have also been shown to be catalytic in the DSSC but are opaque and less conductive.) Carbon nanotube films are much more flexible and less prone to cracking than TCOs, making them ideal candidates for inexpensive roll-to-roll processing and varied installation configurations. Measuring the catalytic performance of nanotube films is crucial to explore methods for increasing their electrochemical activity through film processing. The catalytic activity of single walled carbon nanotube films in DSSCs has been studied by Trancik et al. [83]. Films were made from single-walled carbon nanotubes produced using arc discharge, suspended in a variety of solvents, sonicated and airbrushed onto a substrate placed on a hot plate at $100-150^{\circ} \mathrm{C}$. Such tubes contain metal impurities consisting of nickel and yttrium catalyst particles as well as carbonaceous impurities in the form of amorphous carbon and graphitic nanoparticles. Chemical vapor deposition (CVD) was also used to grow both mats and forests of tubes consisting of long, nanotubes oriented along the plane of the substrate. This allowed to make ultrapure films, due to the extremely low metal (iron) to carbon ratio (metal content $<0.01 \mathrm{wt} \%$ ). By transferring a film of the forest tubes to a conducting glass substrate (using either direct contact or airbrushing tubes in an ethanol solution) and characterizing these samples using electrochemical impedance spectroscopy, it was possible to investigate the impact of metal impurities on the catalytic activity of the films. The reported measurements of the charge-transfer resistance associated with the reduction of triiodide as a function of film transparency and loading demonstrated that exposing the films to UV-generated ozone dramatically increases their catalytic activity, presumably by introducing defects. Ozone-treated tubes show high enough performance to replace platinum in the DSSC. These films could be used to replace both platinum and a TCO in the DSSC. Self assembled nanotube networks in thin films form are expected to facilitate the device fabrication process and provide opportunities for creating high performance solar cell devices with nanoscale building blocks. In this regard Zhu et al. [84] implemented a robust SWNT thin film into in anthocyanin-sensitized solar cells to improve the transport of charge carriers from the light harvesting photoelectrode. Taking advantages of their intrinsic large surface areas and high electron conductivity of carbon nanotubes the authors have fabricated macrofilms of CNTs as counter electrodes, comparing the results with counter electrodes made of multi-walled, double-walled, activated carbon fabrics, and different high surface area carbon blacks were also investigated. Photo electrodes were prepared from a commercial $\mathrm{TiO}_{2}$ powder (Degussa P25, average size $25 \mathrm{~nm}$ ) using a screen printing techniques. The natural dye anthocyanin was extracted from frozen blackberries using methanol/acetic acid/water $(25: 4: 21)$ [85]. The photo electrodes were immersed in the dye solution for at least 3 hours to ensure that the dye molecules were fully absorbed. The raw SWNT macrofilm (about $1 \mu \mathrm{m}$ thick) was deposited on an FTO glass using a floating chemical vapor deposition technique [86], followed by an ethanol wetting in order to enhance the film-substrate adhesion. MWNTs were first treated to remove the catalysts and then stirred to introduce some functional groups and improve the conductivity. A thin film of entangled MWNTs (about $10 \mu \mathrm{m}$ thick) was coated on an FTO glass after completely drying the sample. Vertically aligned DWNT films were prepared on an Alcoated silicon wafer by a water assisted CVD process [87] and then transferred to an FTO glass to make a $10 \mu \mathrm{m}$ thick film after the ethanol wetting. different carbon blacks were tested. Counter electrodes of these carbon blacks were fabricated by mixing $80 \mathrm{wt} \%$ of the carbon black and $20 \mathrm{wt} \%$ of PVDF-HFP binder. A slurry of the above mixture was made using N-methyl-2-pyrrolidone (NMP) as a solvent and this was subsequently brush-coated onto an FTO glass. Compared with the cells using other carbon counter electrodes, the cells with CNT counter electrodes in general show better performance in conversion efficiency $(\eta=1.46 \%$, between 2 and 3 times the value observed with other nanostructures), which can be attributed to the increase in short circuit current density (Jsc). These values are comparable with the highest value ever reported for a cell using a natural dye and Pt counter electrode [88]. Besides the high surface area, the authors argue that the 1D nature of SWNTs significantly contributes to the charge transfer process owing to its improved electric conductivity. The utilization of CNT electrodes affects the kinetics of charge transfer at the electrolyte-carbon interface, as carbon blacks and nanocarbon materials have dissimilar surfaces onto which iodide/iodine absorbed. The contact interface between the counter electrode and surrounding electrolyte is better in CNT materials, which have nanoscale conducting channels and therefore are expected to enhance the electrochemical activity of the electrodes, as demonstrated from the experimental results [86-89]. More recently we have introduced a novel stainless steel cathode coated with commercial non purified SWNTs as an original, stable, lowcost, and high efficient counter electrode for DSSCs [89]. The counter electrodes were prepared by drop casting bundles of Carbolex SWNTs dispersed in water onto an FTO conducting glass or a thin $(2 \mathrm{~mm})$ stainless steel sheet as substrates. SWNTs produced by arc discharge with nominal diameters and lengths range between $d_{t}=1.2-1.5 \mathrm{~nm}$ and $L=2-5 \mu \mathrm{m}$, 
respectively, were used. SWNTs were dispersed in water by ultrasonication without any further pretreatment, and then cast onto the substrate at a temperature of $150^{\circ} \mathrm{C}$. The photoanodes were prepared by depositing $\mathrm{TiO}_{2}$ films on FTO conducting glass. After drying the $\mathrm{TiO}_{2}$, the covered glass plates were sintered in air for 30 minutes at $450^{\circ} \mathrm{C}$, cooled to about $80^{\circ} \mathrm{C}$ and soaked in $\mathrm{N} 3$ dye solution overnight. Measurements on $0.52 \mathrm{~cm}^{2}$ test cells showed a maximum solar energy conversion efficiency of $3.92 \%$ for counter electrodes employing nanotubes on stainless steel, higher than the one obtained with Pt-transparent/FTO counter electrodes, and comparable to the one obtained with $\mathrm{Pt}$ mirrors. The stability test showed no significant change in fill factor, open circuit voltage, short circuit current density, and conversion energy efficiency within 1000 hours (corresponding to 41 days).

\section{Conclusion}

In a typical dye-sensitized solar cell (DSSC), usually platinum has been the preferred material for the counter electrode because of its high electrochemical activity. However, the costs of the platinum prevent the materials from having any large-scale applications in solar cells, thereby forcing the research community to find alternatives. A further problem actually delaying the commercialization of DSSC is the stability of the cell. The efficiency of a DSSC often rapidly drops with time in the initial several days after manufacturing due to the degradation of dye molecules and the reaction of electrolyte with sealing materials or counter electrode. Degradation of the sensitizer, evaporation or leakage of electrolyte solvent and dissolution of $\mathrm{Pt} /$ counter electrode in corrosive iodide/iodine redox electrolyte are some of the facts that deteriorate the long-term DSSC operation. Concerning the counter electrode corrosion, employing the emerging nanotechnologies researcher focused study on advanced nanostructured materials as new cathode materials. In this regard it has been suggested that expensive $\mathrm{Pt}$ counter electrode in DSSC could be replaced by nanosized carbon structures without affecting energy conversion. SWNT and MWNT are found to be competitive with the Pt even when electrode transparency is required. Another new original way to replace conventional cathode materials is to use Pt nanoparticles which combine their porosity and catalytic activity with their crystalline nanostructure. This solution pioneered by our group (work in preparation) could be extended to gold counter electrodes and employed with cobalt-based mediator. We hope this minireview give the opportunity to address new idea and new experiment to realize more stable and low-cost materials for cathode application in DSSCs.

\section{Acknowledgments}

The authors acknowledge Dott. Francesco Bonaccorso for fruitful discussion and Giuseppe Gismondo for technical assistance.

\section{References}

[1] M. Graetzel, "Dye-sensitized solar cells," Journal of Photochemistry and Photobiology C, vol. 4, no. 2, pp. 145-153, 2003.

[2] M. K. Nazeeruddin, A. Kay, I. Rodicio, et al., "Conversion of light to electricity by cis-X2bis $\left(2,2^{\prime}\right.$-bipyridyl-4,4' dicarboxylate)ruthenium(II) charge-transfer sensitizers ( $\mathrm{X}=$ Cl-, Br-, I-, CN-, and SCN-) on nanocrystalline $\mathrm{TiO}_{2}$ electrodes," Journal of the American Chemical Society, vol. 115, no. 14, pp. 6382-6390, 1993.

[3] S. A. Sapp, C. M. Elliott, C. Contado, S. Caramori, and C. A. Bignozzi, "Substituted polypyridine complexes of cobalt(II/III) as efficient electron-transfer mediators in dyesensitized solar cells," Journal of the American Chemical Society, vol. 124, no. 37, pp. 11215-11222, 2002.

[4] S. Anandan, "Recent improvements and arising challenges in dye-sensitized solar cells," Solar Energy Materials and Solar Cells, vol. 91, no. 9, pp. 843-846, 2007.

[5] A. Kay and M. Grätzel, "Low cost photovoltaic modules based on dye sensitized nanocrystalline titanium dioxide and carbon powder," Solar Energy Materials and Solar Cells, vol. 44, no. 1, pp. 99-117, 1996.

[6] Gmelin, Hadbuch der Anorganischen, vol. 68C, Chemie, Weinheim, Germany, 1939.

[7] S. Terauchi, N. Koshizaki, and H. Umehara, "Fabrication of Au nanoparticles by radio-frequency magnetron sputtering," Nanostructured Materials, vol. 5, no. 1, pp. 71-78, 1995.

[8] B. Xu and S.-I. Tanaka, "Formation and bonding of platinum nanoparticles controlled by high energy beam irradiation," Scripta Materialia, vol. 44, no. 8-9, pp. 2051-2054, 2001.

[9] A. Roy, M. Komatsu, K. Matsuishi, and S. Onari, "Raman spectroscopic studies on $\mathrm{Sb}$ nanoparticles in $\mathrm{SiO}_{2}$ matrix prepared by rf-cosputtering technique," Journal of Physics and Chemistry of Solids, vol. 58, no. 5, pp. 741-747, 1997.

[10] K. Eguchi, N. Akasaka, H. Mitsuyasu, and Y. Nonaka, "Process of solid state reaction between doped ceria and zirconia," Solid State Ionics, vol. 135, no. 1-4, pp. 589-594, 2000.

[11] L. Lei and X. Xin, "Solid state synthesis of a new compound $\mathrm{Cu}(\mathrm{HQ}) \mathrm{Cl}_{2}$ and its formation reaction," Thermochimica Acta, vol. 273, no. 1-2, pp. 61-67, 1996.

[12] O. Söhnel and J. Garside, Precipitation, ButterworthHeinemann, 1992.

[13] F. P. Ludwig and J. Schmelzer, Zeitschrift für Physikalische Chemie, vol. 192, p. 155, 1995.

[14] H. Hirai, Y. Nakao, and N. Toshima, "Preparation of colloidal rhodium in poly(vinyl alcohol) by reduction with methanol," Journal of Macromolecular Science. Chemistry, vol. 12, no. 8, pp. 1117-1141, 1978.

[15] H. Hirai, "Formation and catalytic functionality of synthetic polymer-noble metal colloid," Journal of Macromolecular Science. Chemistry, vol. 13, no. 5, pp. 633-649, 1979.

[16] H. Hirai, Y. Nakao, and N. Toshima, "Preparation of colloidal transition metals in polymers by reduction with alcohols or ethers," Journal of Macromolecular Science. Chemistry, vol. 13, no. 6, pp. 727-750, 1979.

[17] J. Turkevich, P. C. Stevenson, and J. Hillier, "A study of the nucleation and growth processes in the synthesis of colloidal gold," Discussions of the Faraday Society, vol. 11, pp. 55-75, 1951.

[18] J. Kimling, M. Maier, B. Okenve, V. Kotaidis, H. Ballot, and A. Plech, "Turkevich method for gold nanoparticle synthesis revisited," Journal of Physical Chemistry B, vol. 110, no. 32, pp. 15700-15707, 2006. 
[19] G. Frens, "Particle size and sol stability in metal colloids," Kolloid-Zeitschrift \& Zeitschrift fur Polymere, vol. 250, no. 7, pp. 736-741, 1972.

[20] B.-K. Pong, H. I. Elim, J.-X. Chong, W. Ji, B. L. Trout, and J.Y. Lee, "New insights on the nanoparticle growth mechanism in the citrate reduction of gold(III) salt: formation of the $\mathrm{Au}$ nanowire intermediate and its nonlinear optical properties," Journal of Physical Chemistry C, vol. 111, no. 17, pp. 62816287, 2007.

[21] K. Aika, L. T. Ban, I. Okura, S. Namba, and J. Turkevich, Journal of the Research Institute for Catalysis, Hokkaido University, vol. 24, p. 54, 1976.

[22] G. Devi and V. J. Rao, "Room temperature synthesis of colloidal platinum nanoparticles," Bulletin of Materials Science, vol. 23, no. 6, pp. 467-470, 2000.

[23] M. Brust, M. Walker, D. Bethell, D. J. Schiffrin, and R. Whyman, "Synthesis of thiol-derivatised gold nanoparticles in a two-phase liquid-liquid system," Journal of the Chemical Society, Chemical Communications, no. 7, pp. 801-802, 1994.

[24] A. Manna, P.-L. Chen, H. Akiyama, T.-X. Wei, K. Tamada, and W. Knoll, "Optimized photoisomerization on gold nanoparticles capped by unsymmetrical azobenzene disulfides," Chemistry of Materials, vol. 15, no. 1, pp. 20-28, 2003.

[25] K. Kurihara, J. Kizling, P. Stenius, and J. H. Fendler, "Laser and pulse radiolytically induced colloidal gold formation in water and in water-in-oil microemulsions," Journal of the American Chemical Society, vol. 105, no. 9, pp. 2574-2579, 1983.

[26] L. Bronstein, E. Kramer, B. Berton, C. Burger, S. Forster, and M. Antonietti, "Successive use of amphiphilic block copolymers as nanoreactors and templates: preparation of porous silica with metal nanoparticles," Chemistry of Materials, vol. 11, no. 6, pp. 1402-1405, 1999.

[27] S. Sato, K. Toda, and S. Oniki, "Kinetic study on the formation of colloidal gold in the presence of acetylenic glycol nonionic surfactant," Journal of Colloid and Interface Science, vol. 218, no. 2, pp. 504-510, 1999.

[28] R. Zanella, S. Giorgio, C.-H. Shin, C. R. Henry, and C. Louis, "Characterization and reactivity in $\mathrm{CO}$ oxidation of gold nanoparticles supported on $\mathrm{TiO}_{2}$ prepared by depositionprecipitation with $\mathrm{NaOH}$ and urea," Journal of Catalysis, vol. 222, no. 2, pp. 357-367, 2004.

[29] W. Chen, W. Cai, L. Zhang, G. Wang, and L. Zhang, "Sonochemical processes and formation of gold nanoparticles within pores of mesoporous silica," Journal of Colloid and Interface Science, vol. 238, no. 2, pp. 291-295, 2001.

[30] C.-L. Chiang, "Controlled growth of gold nanoparticles in AOT/ $\mathrm{C}_{12} \mathrm{E}_{4} /$ isooctane mixed reverse micelles," Journal of Colloid and Interface Science, vol. 239, no. 2, pp. 334-341, 2001.

[31] M. P. Pileni, "Nanosized particles made in colloidal assemblies," Langmuir, vol. 13, no. 13, pp. 3266-3276, 1997.

[32] P. Calandra, A. Longo, and V. Turco Liveri, "Preparation and characterisation of $\mathrm{Na}_{2} \mathrm{~S}$ and $\mathrm{ZnSO}_{4}$ nanoparticles in water/sodium bis(2-ethylhexyl)sulphosuccinate/n-heptane microemulsions," Colloid and Polymer Science, vol. 279, no. 11, pp. 1112-1117, 2001.

[33] P. Calandra, C. Giordano, A. Longo, and V. T. Liveri, "Physicochemical investigation of surfactant-coated gold nanoparticles synthesized in the confined space of dry reversed micelles," Materials Chemistry and Physics, vol. 98, no. 2-3, pp. 494-499, 2006.

[34] J. Zhang, J. Du, B. Han, Z. Liu, T. Jiang, and Z. Zhang, "Sonochemical formation of single-crystalline gold nanobelts," Angewandte Chemie: International Edition, vol. 45, no. 7, pp. 1116-1119, 2006.
[35] N. Robertson, "Optimizing dyes for dye-sensitized solar cells," Angewandte Chemie: International Edition, vol. 45, no. 15, pp. 2338-2345, 2006.

[36] H. S. Wroblowa and A. Saunders, "Flow-through electrodes. II: the $\mathrm{I}_{3}^{-} / \mathrm{I}^{-}$redox couple," Journal of Electroanalytical Chemistry, vol. 42, no. 3, pp. 329-346, 1973.

[37] M. R. Tarasevich and E. I. Khrushcheva, "Electrocatalytic properties of carbon materials," in Modern Aspects of Electrochemistry, B. E. Conway, J. O’M. Bockris, and R. E. White, Eds., vol. 19, p. 295, Plenum Press, New York, NY, USA, 1989.

[38] T. N. Murakami, S. Ito, Q. Wang, et al., "Highly efficient dye-sensitized solar cells based on carbon black counter electrodes," Journal of the Electrochemical Society, vol. 153, no. 12, pp. A2255-A2261, 2006.

[39] K. Imoto, K. Takahashi, T. Yamaguchi, T. Komura, J.-I. Nakamura, and K. Murata, "High-performance carbon counter electrode for dye-sensitized solar cells," Solar Energy Materials and Solar Cells, vol. 79, no. 4, pp. 459-469, 2003.

[40] Z. Huang, X. Liu, K. Li, et al., "Application of carbon materials as counter electrodes of dye-sensitized solar cells," Electrochemistry Communications, vol. 9, no. 4, pp. 596-598, 2007.

[41] K. Li, Z. Yu, Y. Luo, D. Li, and Q. Meng, "Recent progress of counter electrodes in nanocrystalline dye-sensitized solar cells," Journal of Materials Science and Technology, vol. 23, no. 5, pp. 577-582, 2007.

[42] K. Suzuki, M. Yamaguchi, M. Kumagai, and S. Yanagida, "Application of carbon nanotubes to counter electrodes of dye-sensitized solar cells," Chemistry Letters, vol. 32, no. 1, pp. 28-29, 2003.

[43] J. E. Trancik, S. C. Barton, and J. Hone, "Transparent and catalytic carbon nanotube films," Nano Letters, vol. 8, no. 4, pp. 982-987, 2008.

[44] T. Hino, Y. Ogawa, and N. Kuramoto, "Preparation of functionalized and non-functionalized fullerene thin films on ITO glasses and the application to a counter electrode in a dyesensitized solar cell," Carbon, vol. 44, no. 5, pp. 880-887, 2006.

[45] W. Hong, Y. Xu, G. Lu, C. Li, and G. Shi, "Transparent graphene/PEDOT-PSS composite films as counter electrodes of dye-sensitized solar cells," Electrochemistry Communications, vol. 10, no. 10, pp. 1555-1558, 2008.

[46] J. Chen, K. Li, Y. Luo, et al., "A flexible carbon counter electrode for dye-sensitized solar cells," Carbon, vol. 47, no. 11, pp. 2704-2708, 2009.

[47] X. Wang, L. Zhi, and K. Müllen, "Transparent, conductive graphene electrodes for dye-sensitized solar cells," Nano Letters, vol. 8, no. 1, pp. 323-327, 2008.

[48] S. Iijima and T. Ichihashi, "Single-shell carbon nanotubes of 1nm diameter," Nature, vol. 363, no. 6430, pp. 603-605, 1993.

[49] D. S. Bethune, C. H. Kiang, M. S. De Vries, et al., "Cobaltcatalysed growth of carbon nanotubes with single-atomiclayer walls," Nature, vol. 363, no. 6430, pp. 605-607, 1993.

[50] J.-C. Charlier, A. De Vita, X. Blasé, and R. Car, "Microscopic growth mechanisms for carbon nanotubes," Science, vol. 275, no. 5300, pp. 646-649, 1997.

[51] S. Reich, C. Thomsen, and J. Maultzsch, "Carbon nanotubes, basic concepts and physical properties," Journal of Colloid \& Polymer Science, vol. 282, p. 1299, 2004.

[52] S. Iijima, "Helical microtubules of graphitic carbon," Nature, vol. 354 , no. 6348 , pp. 56-58, 1991. 
[53] L. Hu, D. S. Hecht, and G. Gruner, "Percolation in transparent and conducting carbon nanotube networks," Nano Letters, vol. 4, no. 12, pp. 2513-2517, 2004.

[54] G. Che, B. B. Lakshmi, E. R. Fisher, and C. R. Martin, "Carbon nanotubule membranes for electrochemical energy storage and production," Nature, vol. 393, no. 6683, pp. 346-349, 1998.

[55] A. Kongkanand, R. M. Dominguez, and P. V. Kamat, "Single wall carbon nanotube scaffolds for photoelectrochemical solar cells. Capture and transport of photogenerated electrons," Nano Letters, vol. 7, no. 3, pp. 676-680, 2007.

[56] P. V. Kamat, "Harvesting photons with carbon nanotubes," Nano Today, vol. 1, no. 4, pp. 20-27, 2006.

[57] D. M. Guldi, "Nanometer scale carbon structures for chargetransfer systems and photovoltaic applications," Physical Chemistry Chemical Physics, vol. 9, no. 12, pp. 1400-1420, 2007.

[58] Z. Wu, Z. Chen, X. Du, et al., "Transparent, conductive carbon nanotube films," Science, vol. 305, no. 5688, pp. 1273-1276, 2004.

[59] J. M. Planeix, N. Coustel, B. Coq, et al., "Application of carbon nanotubes as supports in heterogeneous catalysis," Journal of the American Chemical Society, vol. 116, p. 7935, 1994.

[60] M. Ambrosio, A. Ambrosio, G. Ambrosone, et al., "Nanotechnology: a new era for photodetection?" Nuclear Instruments and Methods in Physics Research A, vol. 610, no. 1, pp. 1-10, 2009.

[61] P. V. Kamat, M. Haria, and S. Hotchandani, " $\mathrm{C}^{60}$ cluster as an electron shuttle in a $\mathrm{Ru}$ (II)-polypyridyl sensitizer-based photochemical solar cell," Journal of Physical Chemistry B, vol. 108, no. 17, pp. 5166-5170, 2004.

[62] D. M. Guldi and M. Prato, "Excited-state properties of $C^{60}$ fullerene derivatives," Accounts of Chemical Research, vol. 33, no. 10, pp. 695-703, 2000.

[63] H. Hoppe and N. S. Sariciftci, "Organic solar cells: an overview," Journal of Materials Research, vol. 19, no. 7, pp. 1924-1945, 2004.

[64] J. Tersoff and R. S. Ruoff, "Structural properties of a carbonnanotube crystal," Physical Review Letters, vol. 73, no. 5, pp. 676-679, 1994.

[65] A. Thess, R. Lee, P. Nikolaev, et al., "Crystalline ropes of metallic carbon nanotubes," Science, vol. 273, no. 5274, pp. 483-487, 1996.

[66] C. Journet, W. K. Maser, P. Bernier, et al., "Large-scale production of single-walled carbon nanotubes by the electricarc technique," Nature, vol. 388, no. 6644, pp. 756-758, 1997.

[67] A. B. Dalton, S. Collins, E. Muñoz, et al., "Super-tough carbon-nanotube fibres," Nature, vol. 423, no. 6941, p. 703, 2003.

[68] J. N. Coleman, U. Khan, and Y. K. Gun'ko, "Mechanical reinforcement of polymers using carbon nanotubes," Advanced Materials, vol. 18, no. 6, pp. 689-706, 2006.

[69] S. Berber, Y.-K. Kwon, and D. Tománek, "Unusually high thermal conductivity of carbon nanotubes," Physical Review Letters, vol. 84, no. 20, pp. 4613-4616, 2000.

[70] Y.-L. Li, I. A. Kinloch, and A. H. Windle, "Direct spinning of carbon nanotube fibers from chemical vapor deposition synthesis," Science, vol. 304, no. 5668, pp. 276-278, 2004.

[71] K. D. Ausman, R. Piner, O. Lourie, R. S. Ruoff, and M. Korobov, "Organic solvent dispersions of single-walled carbon nanotubes: toward solutions of pristine nanotubes," Journal of Physical Chemistry B, vol. 104, no. 38, pp. 8911-8915, 2000.

[72] S. Giordani, S. D. Bergin, V. Nicolosi, et al., "Debundling of single-walled nanotubes by dilution: observation of large populations of individual nanotubes in amide solvent dispersions," Journal of Physical Chemistry B, vol. 110, no. 32, pp. 15708-15718, 2006.

[73] T. Hasan, P. H. Tan, F. Bonaccorso, et al., "Polymer-assisted isolation of single wall carbon nanotubes in organic solvents for optical-quality nanotube-polymer composites," Journal of Physical Chemistry C, vol. 112, no. 51, pp. 20227-20232, 2008.

[74] T. Hasan, Z. Sun, F. Wang, et al., "Nanotube: polymer composites for ultrafast photonics," Advanced Materials, vol. 21, no. 38-39, pp. 3874-3899, 2009.

[75] M. F. Islam, E. Rojas, D. M. Bergey, A. T. Johnson, and A. G. Yodh, "High weight fraction surfactant solubilization of single-wall carbon nanotubes in water," Nano Letters, vol. 3, no. 2, pp. 269-273, 2003.

[76] W. Wenseleers, I. L. Vlasov, E. Goovaerts, E. D. Obraztsova, A. S. Lobach, and A. Bouwen, "Efficient isolation and solubilization of pristine single-walled nanotubes in bile salt micelles," Advanced Functional Materials, vol. 14, no. 11, pp. 1105-1112, 2004.

[77] Z. Sun, V. Nicolosi, D. Rickard, S. D. Bergin, D. Aherne, and J. N. Coleman, "Quantitative evaluation of surfactant-stabilized single-walled carbon nanotubes: dispersion quality and its correlation with zeta potential," Journal of Physical Chemistry C, vol. 112, no. 29, pp. 10692-10699, 2008.

[78] W. J. Lee, E. Ramasamy, D. Y. Lee, and J. S. Song, "Efficient dyesensitized solar cells with catalytic multiwall carbon nanotube counter electrodes," Applied Materials \& Interfaces, vol. 6, pp. 1145-1149, 2009.

[79] Z. Huang, X. Liu, K. Li, et al., "Application of carbon materials as counter electrodes of dye-sensitized solar cells," Electrochemistry Communications, vol. 9, no. 4, pp. 596-598, 2007.

[80] Q. Wang, H. Li, L. Chen, and X. Huang, "Monodispersed hard carbon spherules with uniform nanopores," Carbon, vol. 39, no. 14, pp. 2211-2214, 2001.

[81] B.-K. Koo, D.-Y. Lee, H.-J. Kim, W.-J. Lee, J.-S. Song, and H.-J. Kim, "Seasoning effect of dye-sensitized solar cells with different counter electrodes," Journal of Electroceramics, vol. 17, no. 1, pp. 79-82, 2006.

[82] K. Suzuki, M. Yamaguchi, M. Kumagai, and S. Yanagida, "Application of carbon nanotubes to counter electrodes of dye-sensitized solar cells," Chemistry Letters, vol. 32, no. 1, pp. 28-29, 2003.

[83] J. E. Trancik, S. C. Barton, and J. Hone, "Transparent and catalytic carbon nanotube films," Nano Letters, vol. 8, no. 4, pp. 982-987, 2008.

[84] H. Zhu, H. Zeng, V. Subramanian, C. Masarapu, K.-H. Hung, and B. Wei, "Anthocyanin-sensitized solar cells using carbon nanotube films as counter electrodes," Nanotechnology, vol. 19, no. 46, Article ID 465204, 2008.

[85] N. J. Cherepy, G. P. Smestad, M. Graetzel, and J. Z. Zhang, "Ultrafast electron injection: implications for a photoelectrochemical cell utilizing an anthocyanin dye-sensitized $\mathrm{TiO}_{2}$ nanocrystalline electrode," Journal of Physical Chemistry B, vol. 101, no. 45, pp. 9342-9351, 1997.

[86] H. W. Zhu and B. Q. Wei, "Direct fabrication of single-walled carbon nanotube macro-films," Chemical Communications, vol. 29, pp. 3042-3044, 2007.

[87] L. Ci, R. Vajtai, and P. M. Ajayan, "Vertically aligned large-diameter double-walled carbon nanotube arrays having ultralow density," Journal of Physical Chemistry C, vol. 111, no. 26, pp. 9077-9080, 2007. 
[88] H. L. Wei, H. S. Yen, G. T. Lay, and H. H. Min, "Commercial and natural dyes as photosensitizers for a water-based dyesensitized solar cell loaded with gold nanoparticles," Journal of Photochemistry and Photobiology, vol. 195, pp. 307-313, 2008.

[89] G. Calogero, F. Bonaccorso, O. M. Maragò, P. G. Gucciardi, and G. Di Marco, "Single wall carbon nanotubes deposited on stainless steel sheet substrates as novel counter electrodes for ruthenium polypyridine based dye sensitized solar cells," Dalton Transactions, vol. 39, no. 11, pp. 2903-2909, 2010. 


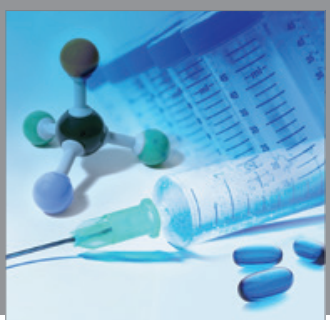

International Journal of

Medicinal Chemistry

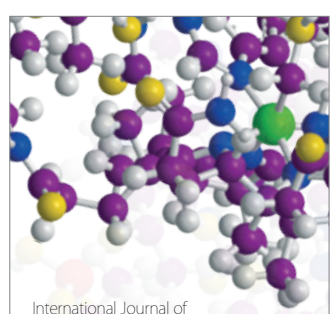

Carbohydrate Chemistry

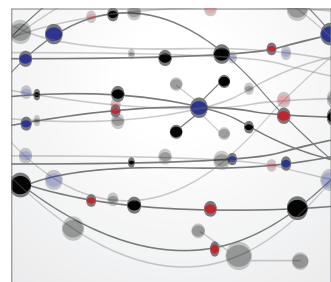

The Scientific World Journal
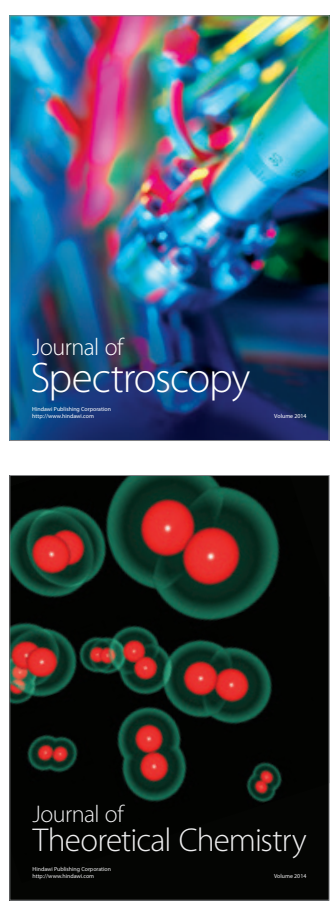
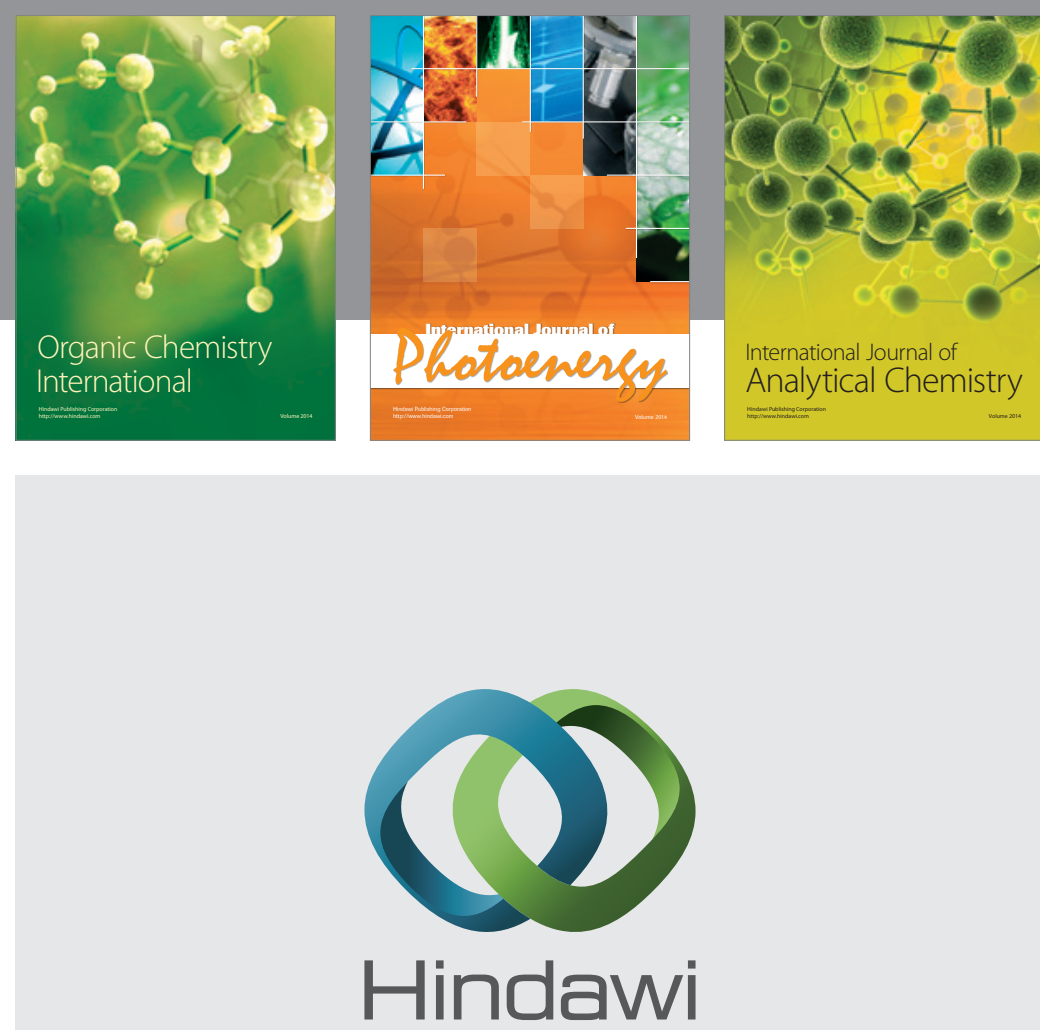

Submit your manuscripts at

http://www.hindawi.com
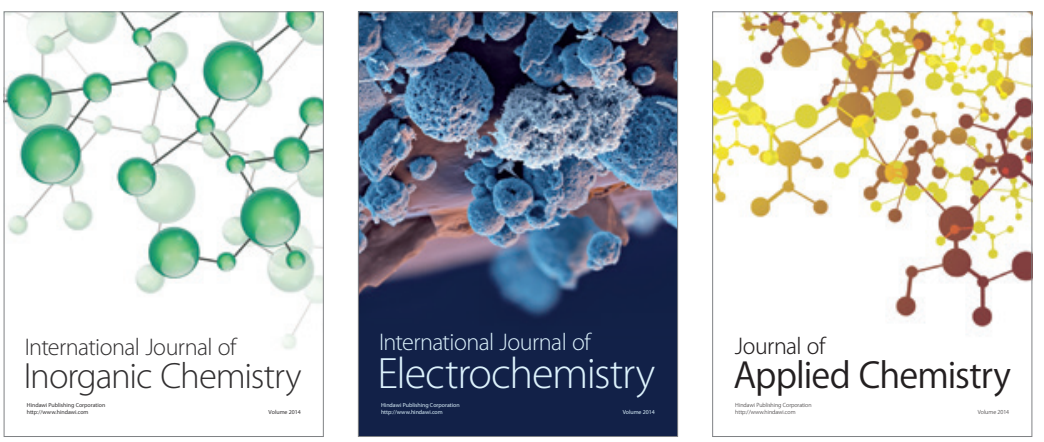

Journal of

Applied Chemistry
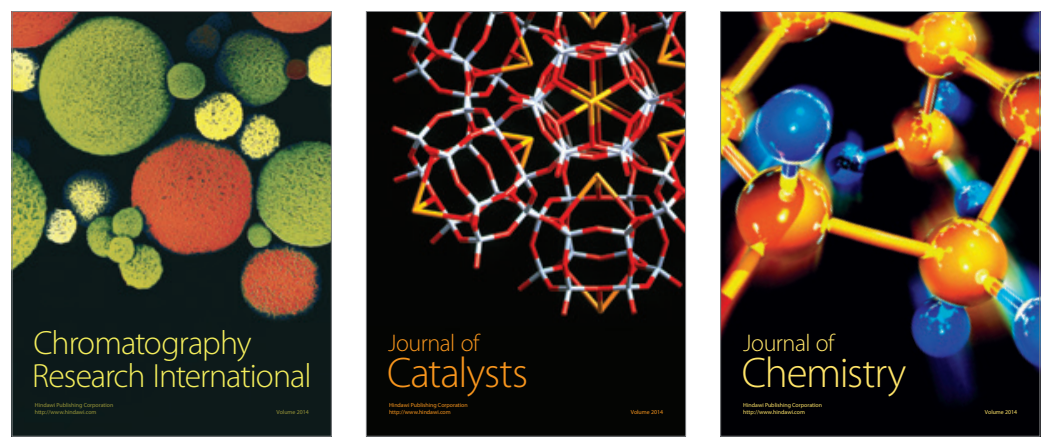
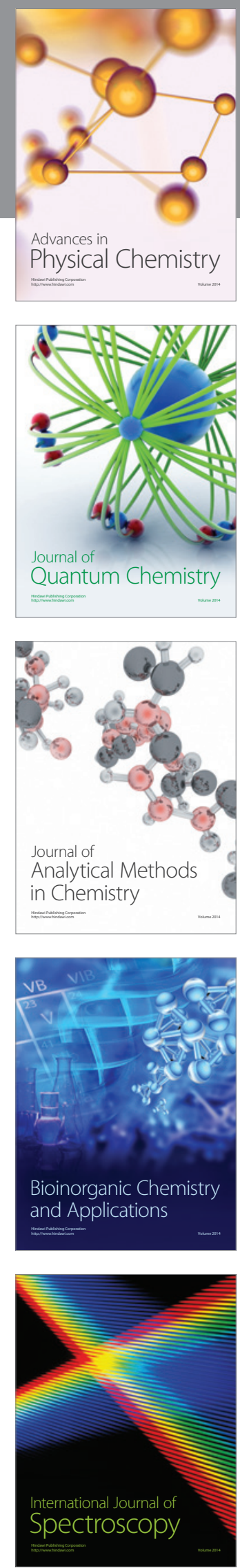